\title{
Synthesis gas production using oxygen storage materials as oxygen carrier over circulating fluidized bed
}

\author{
DAI Xiaoping (代小平) ${ }^{1,2}$, YU Changchun (余长春) ${ }^{1}$, LI Ranjia (李然家) ${ }^{1}$, WU Qiong (吴 琼) ${ }^{1}$, \\ HAO Zhengping (郝郑平) ${ }^{2}$
}

(1. The Key Laboratory of Catalysis CNPC, University of Petroleum, Beijing 102249, China; 2. Research Center for Eco-Environmental Science, Chinese Academy of Sciences, Beijing 100085, China)

Received 6 June 2007; revised 19 October 2007

\begin{abstract}
A novel process for synthesis gas production over Circulating Fluidized Bed (CFB) using oxygen storage materials as oxygen carrier was reported. First, oxygen in the air was chemically fixed and converted to lattice oxygen of oxygen storage materials over regenerator, and then methane was selectively oxidized to synthesis gas with lattice oxygen of oxygen storage materials over riser reactor. The results from simulation reaction of $\mathrm{CFB}$ by sequential redox reaction on a fixed bed reactor using lanthanum-based perovskite $\mathrm{LaFeO}_{3}$ and $\mathrm{La}_{0.8} \mathrm{Sr}_{0.2} \mathrm{Fe}_{0.9} \mathrm{Co}_{0.1} \mathrm{O}_{3}$ oxides prepared by sol-gel, suggested that the depleted oxygen species could be regenerated, and methane could be oxidized to synthesis gas by lattice oxygen with high selectivity. The partial oxidation of methane to synthesis gas over CFB using lattice oxygen of the oxygen storage materials instead of gaseous oxygen should be possibly applicable.
\end{abstract}

Keywords: oxygen storage materials; air separation; partial oxidation; synthesis gas; circulating fluidized bed; rare earths

Methane was extensively used as an energy source and in the production of fine chemicals. Nowadays, much attention has been paid to produce synthesis gas more efficiently by Partial Oxidation of Methane (POM) than Steam Methane Reforming (SMR) ${ }^{[\prime]}$. POM can be carried out at lower investment and produce synthesis gas with a $\mathrm{H}_{2} / \mathrm{CO}$ ratio of ca. 2, which was suitable for methanol and Fischer-Tropsch synthesis $^{[2]}$. Ni metal has been reported as the most promising catalyst system for commercialization ${ }^{[3]}$; however, there are major drawbacks with Ni metal catalysts, such as phase transformation $^{[4]}$, coke deposition, $\mathrm{Ni}$ sintering ${ }^{[5]}$ and $\mathrm{Ni}$ losses $^{[0]}$. But synthesis gas production accounted for about half of the capital investment in gas to liquid (GTL) process, in part due to significant capital cost of the oxygen plant. Not surprisingly, oxygen plant investment has been an attractive target of GTL cost-cutting strategies. Many researchers paid their efforts to develop new technologies for cost reduction, such as two-stage fixed bed process ${ }^{[7]}$, oxygen ion transport membrane technology (ITM) ${ }^{[8-10]}$, two-step cyclic processes with steam ${ }^{[11]}$, gas-solid reaction between methane and cerium oxide $\left(\mathrm{CeO}_{2}\right)^{[12-14]}$, unsteady-state direct partial oxidation of methane to synthesis gas in a fixed-bed reactor ${ }^{[15,16]}$. Keller et al. ${ }^{[17]}$ performed successfully catalytic oxidative coupling of methane by redox cycle of metal oxides, and circulating fluidized bed technology has been successfully applied in selective oxidation of $n$-butane to maleic anhydride ${ }^{[18]}$. Based on the idea of CFB process, a novel process for synthesis gas production via partial oxidation of methane using oxygen storage materials as oxygen carrier over CFB, which eliminated the oxygen equipment, was proposed in this paper, and the process was simulated by sequential redox reaction over a fixed bed reactor using lanthanum-transition metal perovskite oxide as oxygen carrier.

\section{Experimental}

\subsection{Material preparation}

Sol-gel method was employed to prepare the samples. Powders of $\mathrm{La}\left(\mathrm{NO}_{3}\right)_{3} \cdot 6 \mathrm{H}_{2} \mathrm{O}, \quad \mathrm{Fe}\left(\mathrm{NO}_{3}\right)_{3} \cdot 9 \mathrm{H}_{2} \mathrm{O}$, $\mathrm{Co}\left(\mathrm{NO}_{3}\right)_{3} \cdot 6 \mathrm{H}_{2} \mathrm{O}$ and $\mathrm{Sr}\left(\mathrm{NO}_{3}\right)_{2}(>99 \%$, Beijing Chemical Company) were weighed and dissolved in a small amount of

Foundation item: Project supported by the National Natural Science Foundation of China $(20306016,20322201)$

Corresponding author: HAO Zhengping; YU Changchun (E-mail: zpinghao@rcees.ac.cn; lngcc@cup.edu.cn; Tel.: +86-10-89707447; +86-10-62923564) 
distilled water. Glycine ( $>99 \%$, Beijing Chemical Company) was kept at a ratio of $\mathrm{NH}_{3} / \mathrm{NO}_{3}=1.05$ to prepare the gel. Gelation was induced by heating the solution at $353-363 \mathrm{~K}$; this temperature was maintained for $10 \mathrm{~h}$, and then heated at $523 \mathrm{~K}$ for $30 \mathrm{~min}$ with a fast decomposition reaction, upon which dried powder precursor was obtained. The obtained precursor was then fired in a muffle oven at $1173 \mathrm{~K}$ for $5 \mathrm{~h}$ with a heating rate of $10 \mathrm{~K} / \mathrm{min}$.

\subsection{Material characterization}

Powder X-Ray Diffraction (XRD) patterns were recorded from $2 \theta=20^{\circ}$ to $80^{\circ}$ with a speed of $4\left({ }^{\circ}\right) / \mathrm{min}$ and $0.02^{\circ}$ step size using ShiDU XRD-6000 powder diffractometer employing $\mathrm{Ni}$-filtered $\mathrm{Cu} \mathrm{K} \alpha$ radiation.

X-ray photoelectron spectra were obtained with VG ESCA LAB 210 system using $\mathrm{Mg} \mathrm{Ka}$ radiation under ultrahigh vacuum $\left(5 \times 10^{-9} \mathrm{~Pa}\right)$. The spectra were calibrated relatively to $C\left(1 s_{1 / 2}\right)$ bond energy of contamination carbon, which was fixed at $284.6 \mathrm{eV}$.

\subsection{Simulation reaction of CFB over a fixed bed reactor}

Simulation reaction of CFB over fixed bed reactor by sequential redox reaction for the production of synthesis gas using oxygen storage materials, such as lanthanum-based perovskite $\mathrm{LaFeO}_{3}$ and $\mathrm{La}_{0.8} \mathrm{Sr}_{0.2} \mathrm{Fe}_{0.9} \mathrm{Co}_{0.1} \mathrm{O}_{3}$, were performed in fixed bed reactor at $1173 \mathrm{~K}$ between reductive $\left(\mathrm{CH}_{4} / \mathrm{He}\right)$ and oxidative atmospheres $\left(\mathrm{O}_{2} / \mathrm{Ar}\right)$. The total gas flow rate was kept at $23 \mathrm{ml} / \mathrm{min}$. Ar/He was used as dilution gas and tracer gas.

The reactant and products were detected by mass spectrometer at $m / e=2\left(\mathrm{H}_{2}\right)$, m/e=15 $\left(\mathrm{CH}_{4}\right)$, m/e $=18\left(\mathrm{H}_{2} \mathrm{O}\right)$, $m / e=28\left(\mathrm{CO}\right.$ and $\left.\mathrm{CO}_{2}\right), m / e=32\left(\mathrm{O}_{2}\right)$ and $m / e=44\left(\mathrm{CO}_{2}\right)$. Pure $\mathrm{CH}_{4}, \mathrm{CO}, \mathrm{H}_{2}$ and $\mathrm{CO}_{2}$ pulses were injected in order to calculate the amount of $\mathrm{CH}_{4}, \mathrm{CO}$ and $\mathrm{CO}_{2}$ on the oxides taking into account a previous calibration of the mass spectrometer. Calibration of the mass spectrometer was carried out with standard gas mixtures (known composition). Cracking coefficients of methane, $\mathrm{CO}$ and $\mathrm{CO}_{2}$ were determined and used to calculate their concentrations. The $\mathrm{CO}$ selectivity was defined as $\mathrm{CO} /\left(\mathrm{CO}+\mathrm{CO}_{2}+\mathrm{C}\right) \times 100 \%$.

\section{Results and discussion}

\subsection{Process concept}

The process, based on redox reactions over oxygen storage materials, such as lanthanum-transition metal perovskite composite oxides, which usually exhibit excellent redox property, high oxygen mobility, thermal stability and good capacity of oxygen suppliers, can be carried out over CFB, as shown in Fig.1.

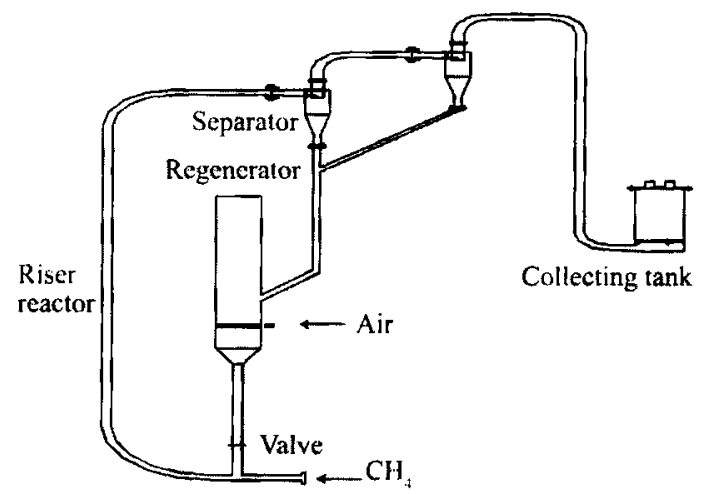

Fig.1 Schematic process of circulating fluidized bed (CFB)

First, oxygen in the air is chemically fixed and converts to lattice oxygen of oxygen storage materials over regenerator, and then methane is selectively oxidized to synthesis gas by oxygen species of oxygen storage materials over riser reactor. The reduced oxide from the riser top is separated from the product stream, and returns to the regenerator for reoxidation. The oxide goes through an oxidation/reduction cycle each time, and it circulates around the loop. The process achieves in situ separation of oxygen from air, and eliminates the equipment for air separate. The yield losses attribute to gas backmixing can be minimized by optimization the reaction conditions. The main catalytic reactions involve in this process for synthesis gas production are oxidation reaction of methane with oxygen species, regeneration of lattice oxygen with gaseous oxygen or air.

The reduction step over riser reactor: $\mathrm{CH}_{4}+[\mathrm{O}]_{\mathrm{L}} \rightarrow \mathrm{CO}+\mathrm{H}_{2}+\mathrm{CO}_{2}+\mathrm{H}_{2} \mathrm{O}+[]_{\mathrm{L}}$

The re-oxidation step of reduced oxide over regenerator:

[]$_{L}+$ Air $\rightarrow\left[\mathrm{O}_{L}+\mathrm{N}_{2}\right.$

where $[\mathrm{O}]_{\mathrm{L}}$ is lattice oxygen and [ $]_{\mathrm{L}}$ is oxygen vacancy.

According to Mars-Van-Krevelen mechanism ${ }^{[19]}$, two independent steps should be distinguished as $\mathrm{CH}_{4}$ oxidation reaction and oxygen regenerated by redox cycles:

$\mathrm{CH}_{4}+\mathrm{O}_{\mathrm{L}}{ }^{*} \rightarrow$ Pro $+\left[{ }^{*}\right]$

$2\left[{ }^{*}\right]+\mathrm{O}_{2} \rightarrow 2\left[\mathrm{O}_{\mathrm{L}}\right]^{*}$

where Pro is the products, $\mathrm{O}^{*}$ is the oxidized sites, and $\left.{ }^{*}\right]$ is the reduced sites. The CFB process allows continuous regeneration of catalyst. Better catalytic performance for partial oxidation of methane can be obtained because it allows separating optimization of the reduction and oxidation steps. A sweeping step with inert gases between reduction and oxidation steps for desorption of adsorbed oxygen on the surface is involved. These measures can reduce total oxidation of methane, and increase CO selectivity. The CFB process avoids many of the negatives of the fixed bed and fluidized bed reactors (such as efficient heat removal and ease of temperature control), and offers some added advan- 
tages (such as relatively little backmixing) ${ }^{[20]}$. Therefore, this new process is superior to general POM in stability (resistance to carbonaceous deposition due to periodical regeneration), safety (effectively avoiding accidental explosion), high selectivity (inhibition of non-selective oxidation as the absence of gaseous oxygen), ease of operation and optimization, and low cost (making use of air not oxygen). Of course, carbon resistance, the amount of reversible absorbed/desorbed oxygen species, and attrition resistance about the oxygen storage materials are the key technology for the production of synthesis gas over CFB process.

\subsection{Simulation reaction of CFB over fixed bed reactor}

Simulation reactions of CFB on fixed bed reactor by sequential redox reaction over $0.25 \mathrm{~g} \quad \mathrm{LaFeO}_{3}$ and $\mathrm{La}_{0.8} \mathrm{Sr}_{0.2} \mathrm{Fe}_{0.9} \mathrm{Co}_{0.1} \mathrm{O}_{3}$ oxides were performed at $1173 \mathrm{~K}$ between $\mathrm{O}_{2} / \mathrm{Ar}\left(11 \% \mathrm{O}_{2}\right.$ by mole, $\left.10 \mathrm{~s}\right)$ and $\mathrm{CH}_{4} / \mathrm{He}\left(11 \% \mathrm{CH}_{4}\right.$ by mole, $30 \mathrm{~s}$ ). The reaction temperature was determined previously to produce a level of conversion suitable for study, and the results are shown in Figs. 2 and 3.

Fig. 2 indicates reactants and products responses during sequential redox between $\mathrm{O}_{2} / \mathrm{Ar}$ oxidation and $\mathrm{CH}_{4} / \mathrm{He}$ reduction over oxygen storage materials at $1173 \mathrm{~K}$. In the first cycle, methane is oxidized totally firstly by very reactive oxygen species over fresh oxygen storage materials, forming firstly $\mathrm{CO}_{2}$ and $\mathrm{H}_{2} \mathrm{O}$, and then $\mathrm{CO}$ and $\mathrm{H}_{2}$ are detected when the concentration of very reactive oxygen species declines. Most of the oxygen species, which can react with $\mathrm{CH}_{4}$ to form synthesis gas, can be regenerated again by gaseous oxygen during re-oxidation step. From the second redox cycle, methane conversion enhances slowly, and the intensity of $\mathrm{CO}_{2}$ declines slightly with increasing the redox cycles, while the selectivity of $\mathrm{CO}$ increases, and synthesis gas are the dominant products. But $\mathrm{CO}$ intensity declines slightly from the 16th cycle, while the intensity of $\mathrm{H}_{2}$ keeps constant over $\mathrm{La}_{0.8} \mathrm{Sr}_{0.2} \mathrm{Fe}_{0.9} \mathrm{Co}_{0.1} \mathrm{O}_{3}$ oxide, which indicates that methane decomposition occurs. From the response curve of oxygen $(m / e=32$ ), oxygen storage materials have high reactivity with gaseous oxygen, which is not detected during sequential redox reaction. The above results indicate that the less reactive oxygen species for the $\mathrm{CO}$ formation can be regenerated, while the very reactive oxygen species for the $\mathrm{CO}_{2}$ formation is recovered hardly at reaction condition. The partial oxidation of methane using lattice oxygen of the oxygen storage materials instead of gaseous oxygen should be possible. Fig. 3 shows variation of $\mathrm{CH}_{4}$ conversion and selectivity for $\mathrm{CO}$ as a function of redox cycles. $\mathrm{LaFeO}_{3}$ oxide exhibits better catalytic activity for synthesis gas production than that of $\mathrm{La}_{0.8} \mathrm{Sr}_{0.2} \mathrm{Fe}_{0.9} \mathrm{Co}_{0.1} \mathrm{O}_{3}$ oxide. The $\mathrm{CH}_{4}$ conversions remains at $60 \%-70 \%$ and the selectivities to $\mathrm{CO}$ remained at higher level $\left(>96 \%\right.$ ) over $\mathrm{LaFeO}_{3}$ oxide, while the selectivities of $\mathrm{CO}$ decrease sharply over $\mathrm{La}_{0.8} \mathrm{Sr}_{0.2} \mathrm{Fe}_{0.9} \mathrm{Co}_{0.1} \mathrm{O}_{3}$ oxide from the 6th cycle. The intensi-
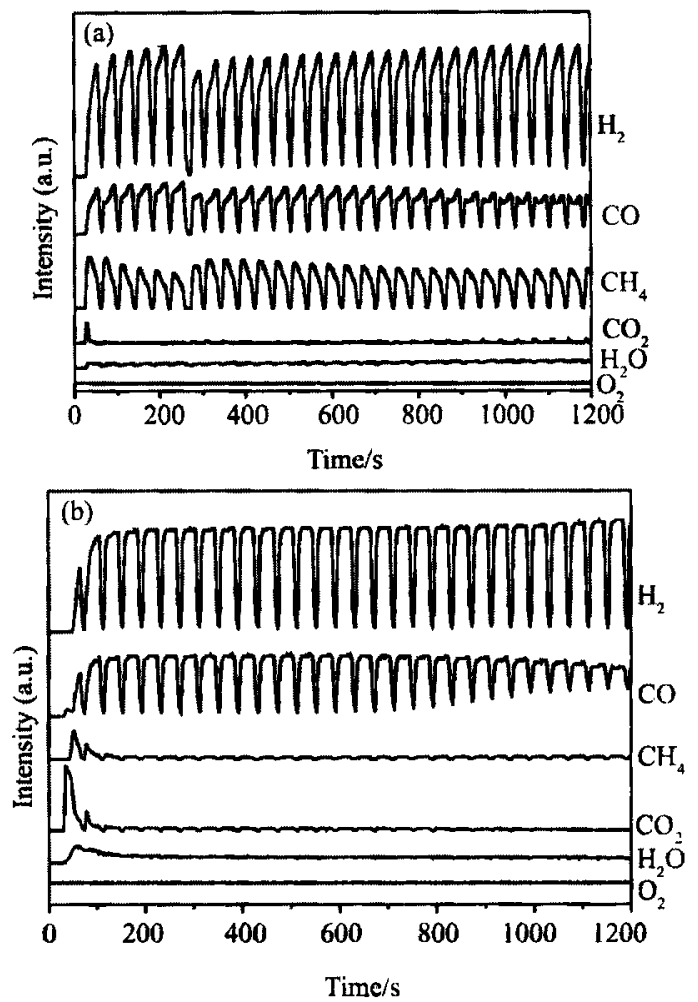

Fig. 2 Results of simulation reaction of CFB on fixed bed reactor by sequential redox reaction using oxygen storage materials (Reaction conditions: sample mass $0.25 \mathrm{~g}$, atmospheric pressure, $1173 \mathrm{~K}$ )

(a) $\mathrm{LaFeO}_{3}$; (b) $\mathrm{La}_{0.8} \mathrm{Sr}_{0.2} \mathrm{Fe}_{0.9} \mathrm{Co}_{0.1} \mathrm{O}_{3}$

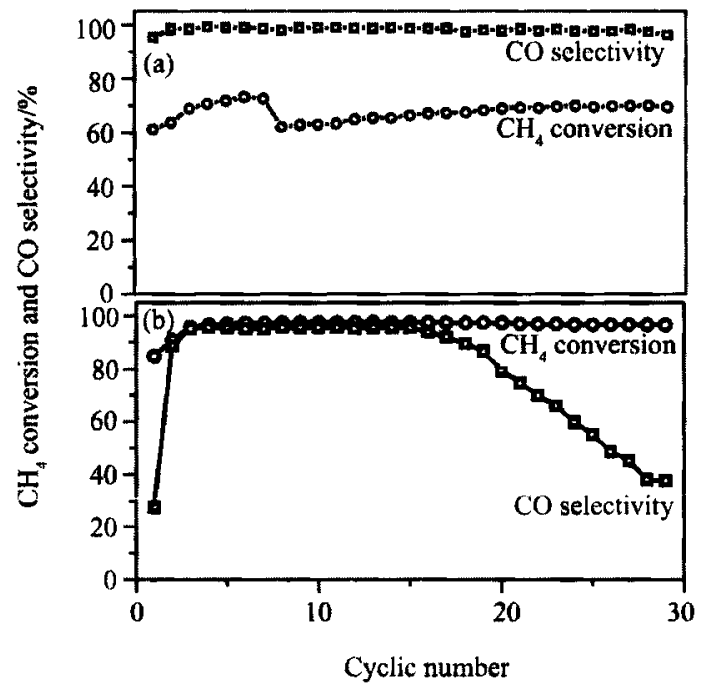

Fig. $3 \mathrm{CH}_{4}$ conversion, $\mathrm{CO}$ selectivity vs. cyclic number using oxygen storage materials (Reaction conditions: sample mass 0.25 g, atmospheric pressure, $1173 \mathrm{~K}$ )

(a) $\mathrm{LaFeO}_{3}$; (b) $\mathrm{La}_{0.8} \mathrm{Sr}_{0.2} \mathrm{Fe}_{0.9} \mathrm{Co}_{0.1} \mathrm{O}_{3}$ 
ties of $\mathrm{CO}_{2}$ and $\mathrm{H}_{2}$ changes hardly, while the intensity of $\mathrm{CO}$ decrease sharply over $\mathrm{La}_{0.8} \mathrm{Sr}_{0.2} \mathrm{Fe}_{0.9} \mathrm{Co}_{0.1} \mathrm{O}_{3}$ oxide from the 6th cycle, which implies that carbon is deposited on the oxide during methane reaction step under the reaction conditions.

The amounts of Oxygen Storage Capacity (OSC) by sequential redox cycle are shown in Table 1. The results show that the amount of oxygen species for $\mathrm{CO}$ formation increases slightly with increasing redox cycle, and keeps constant for $\mathrm{LaFeO}_{3}$ oxide, while the amount of oxygen species for $\mathrm{CO}$ formation increases sharply with increasing redox cycle, and then drops for $\mathrm{La}_{0.8} \mathrm{Sr}_{0.2} \mathrm{Fe}_{0.9} \mathrm{Co}_{0.1} \mathrm{O}_{3}$ oxide. The trend of the amount of oxygen species for $\mathrm{CO}$ formation can be relevant with the structural change of $\mathrm{La}_{0.8} \mathrm{Sr}_{0.2} \mathrm{Fe}_{0.9} \mathrm{Co}_{0.1} \mathrm{O}_{3}$ oxide (as shown in Fig.4). The comparison of XRD spectra between pre- and post-reaction oxygen storage materials over fixed bed reactor for sequential redox cycle is shown in Fig.4. The results show that preand post-reaction $\mathrm{LaFeO}_{3}$ oxides are single-phase perovskites, while new XRD peaks $\left(\mathrm{La}_{2} \mathrm{O}_{3}, \mathrm{SrO}, \mathrm{CoO}\right.$, $\mathrm{Co}_{3} \mathrm{O}_{4}, \quad \mathrm{Fe}_{2} \mathrm{O}_{3}, \quad$ and $\mathrm{Fe}_{3} \mathrm{O}_{4}$ ) appeared over $\mathrm{La}_{0.8} \mathrm{Sr}_{0.2} \mathrm{Fe}_{0.9} \mathrm{Co}_{0.1} \mathrm{O}_{3}$ oxide, and perovskite phase disappears, which results in the declining performance of selective oxidation.

Table 1 Oxygen storage capacity for CO formation by sequential redox cycle*

\begin{tabular}{llllll}
\hline Catalyst & $\begin{array}{l}1 \text { th } \\
\text { cycle }\end{array}$ & $\begin{array}{l}3 \text { th } \\
\text { cycle }\end{array}$ & $\begin{array}{l}15 \text { th } \\
\text { cycle }\end{array}$ & $\begin{array}{l}\text { 22th } \\
\text { cycle }\end{array}$ & $\begin{array}{l}29 \text { th } \\
\text { cycle }\end{array}$ \\
\hline $\mathrm{LaFeO}_{3}$ & 55.8 & 65.0 & 63.7 & 64.8 & 64.1 \\
$\mathrm{La}_{0.8} \mathrm{Sr}_{0.2} \mathrm{Fe}_{0.9} \mathrm{CO}_{0.1} \mathrm{O}_{3}$ & 22.3 & 87.4 & 89.4 & 65.0 & 35.0 \\
\hline
\end{tabular}

* Unit: $\mu \mathrm{mol} / \mathrm{g}$ catalyst

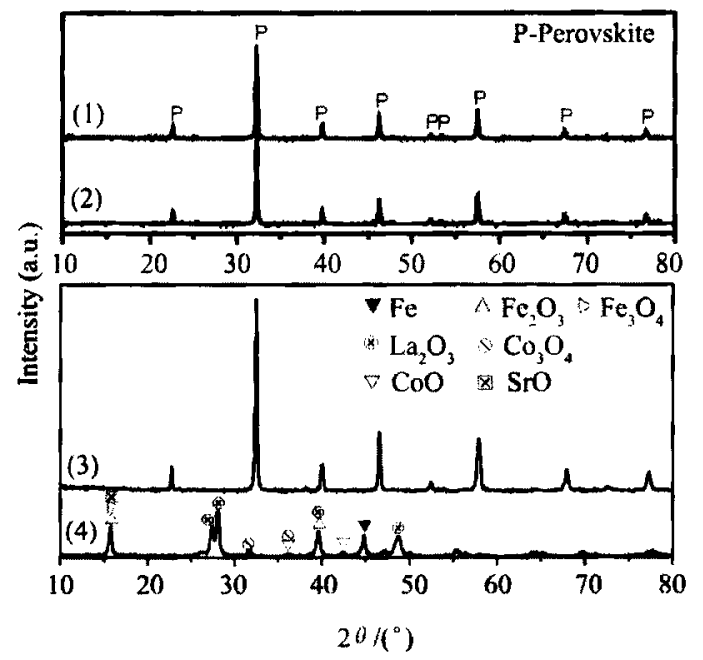

Fig.4 Comparison of XRD profile between pre- and post-reaction lanthanum-based perovskite oxides

(1) Post-reaction $\mathrm{LaFeO}_{3}$; (2) Pre-reaction $\mathrm{LaFeO}_{3}$; (3) Pre-reaction $\mathrm{La}_{0.8} \mathrm{Sr}_{0.2} \mathrm{Fe}_{0.9} \mathrm{Co}_{0.1} \mathrm{O}_{3}$; (4) Post-reaction $\mathrm{La}_{0.8} \mathrm{Sr}_{0.2} \mathrm{Fe}_{0.9} \mathrm{Co}_{0.1} \mathrm{O}_{3}$

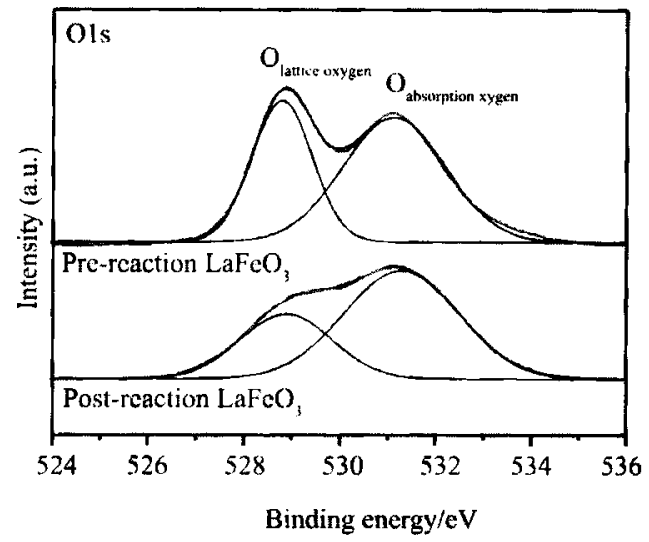

Fig. 5 XPS of $\mathrm{O}_{1 \mathrm{~s}}$ over pre-and post-reaction $\mathrm{LaFeO}_{3}$ oxides

The depletion of lattice oxygen has been confirmed by XPS measurements on pre- and post-reaction $\mathrm{LaFeO}_{3}$ oxides over fixed bed reactor, as shown in Fig. 4. The oxide reacts with $\mathrm{CH}_{4} / \mathrm{Ar}$ for $75 \mathrm{~s}$ at $1173 \mathrm{~K}$ then changing to He during cooling to room temperature. XPS analysis of the $\mathrm{O}_{\mathrm{ls}}$ core level spectra shows that it is composed of two peaks, indicating that two types of oxygen presented on the pre- and post-reaction $\mathrm{LaFeO}_{3}$ oxides surface. These two oxygen species can be defined as very reactive oxygen species for $\mathrm{CO}_{2}$ formation and less reactive oxygen species for synthesis gas formation. The line at ca. $528.9 \mathrm{eV}$ is assigned to oxygen in the lattice and the one at ca. $531.1 \mathrm{eV}$ to adsorbed oxygen-containing species ${ }^{[2]]}$. It is clear that the lattice oxygen decreases after reacting with $11 \mathrm{~mol} . \% \mathrm{CH}_{4} / \mathrm{Ar}$ at 1173 $\mathrm{K}$. The amount of adsorbed oxygen containing species is difficult to determine since the oxides are inevitable due to contact with air. This is consistent with the results obtained from the first redox cycle reaction, which indicated that $\mathrm{CO}_{2}$ forms firstly and then $\mathrm{CO}$ product.

Therefore, the research work to improve the migration rate, oxygen storage capacity, structural stability, carbon resistance and attrition resistance for CFB process is still going on. Significant progress has been made toward developing improved materials and suitable cycles that avoid combustion and carbon formation, and maximize synthesis gas yield.

\section{References:}

[1] Dissanayake D, Rosynek M P, Kharas K C C, Lunsford J H. Partial oxidation of methane to carbon monoxide and hydrogen over a Ni/Al ${ }_{2} \mathrm{O}_{3}$ catalyst. J. Catal., 1991, 132(1): 117.

[2] Bharadwaj S S, Schmidt L D. Synthesis gas formation by catalytic oxidation of methane in fluidized bed reactors. $J$. Catal., 1994, 146(1): 11.

[3] Fei Y N, Shen M Q, Shi F L, W J, W D. Influence of $\mathrm{CeO}_{2-}$ 
$\mathrm{ZrO}_{2}$ and $\alpha-\mathrm{Al}_{2} \mathrm{O}_{3}$ on methane partial oxidation over Ni catalyst. J. Rare Earths, 2006, 24(S2): 100.

[4] Natesakhawat S, Watson R B, WANG X Q, Ozkan U S. Deactivation characteristics of lanthanide-promoted sol-gel $\mathrm{Ni} / \mathrm{Al}_{2} \mathrm{O}_{3}$ catalysts in propane steam reforming. J. Catal., 2005 , 234(2): 496.

[5] Ji Y Y, Li W Z, Xu H Y, Chen Y X. Catalytic partial oxidation of methane to synthesis gas over $\mathrm{Ni} / \gamma-\mathrm{Al}_{2} \mathrm{O}_{3}$ catalyst in a fluidized-bed. Appl. Catal. A., 2001, 213(1): 25.

[6] Hu Y H, Ruckenstein E J. Transient kinetic studies of partial oxidation of $\mathrm{CH}_{4}$. J. Catal., 1996, 158 (1): 260.

[7] Dai X P, Yu C C, Li Q, Zhang C B, Jiang Q Y, Shen S K. An integrated process of a two-stage fixed bed syngas production and F-T synthesis for GTL in remote gas field. Chinese $J$. Chem. Eng., 2003, $11(1): 85$.

[8] Mazanec T J, Cable T L. Electrocatalytic oxidative dehydrogenation of saturated hydrocarbons to unsaturated hydrocarbons. US Patent 4,933,054. 1990.

[9] Shao Z P, Yang W S, Cong Y, Dong H, Tong J H, Xiong G X. Investigation of the permeation behavior and stability of a $\mathrm{Ba}_{0.5} \mathrm{Sr}_{0.5} \mathrm{Co}_{0.8} \mathrm{Fe}_{0.2} \mathrm{O}_{3-8}$ oxygen membrane. J. Membrane Sci., 2000, 172(1-2): 177.

[10] Wu Z T, Jin W Q, Xu N P. Oxygen permeability and stability of $\mathrm{Al}_{2} \mathrm{O}_{3}$-doped $\mathrm{SrCo}_{0.8} \mathrm{Fe}_{0.2} \mathrm{O}_{3-8}$ mixed conducting oxides. $J$. Membrane Sci., 2006, 279(1-2): 320.

[11] Kodama T, Shimizu T, Satoh T, Shimizu K I. Stepwise production of CO-rich syngas and hydrogen via methane reforming by a $\mathrm{WO}_{3}$-redox catalyst. Energy, 2003, 28(11): 1055.

[12] Otsuka K, Wang Y, Sunada E, Yamanaka I. Direct partial oxidation of methane to synthesis gas by cerium oxide. J. Catal., 1998, 175(2): 152

[13] Otsuka K, Wang Y, Nakamura M. Direct conversion of methane to synthesis gas through gas-solid reaction using $\mathrm{CeO}_{2}-\mathrm{ZrO}_{2}$ solid solution at moderate temperature. Appl. Catal. A, 1999, 183(2): 317.

[14] Fathi M, Bjorgum E, Viig T, Rokstad O A. Partial oxidation of methane to synthesis gas: Elimination of gas phase oxygen. Catal. Today, 2000, 63(2-4): 489.

[15] Dai X P, Li R J, Yu C C, Hao Z P. Unsteady-state direct partial oxidation of methane to synthesis gas in a fixed-bed reactor using $\mathrm{AFeO}_{3}(\mathrm{~A}=\mathrm{La}, \mathrm{Nd}, \mathrm{Eu})$ perovskite-type oxides as oxygen storage. J. Phys. Chem. B, 2006, 110(45): 22525.

[16] Dai X P, Wu Q, Li R J, Yu C C, Hao Z P. Hydrogen production from a combination of the water-gas shift and redox cycle process of methane partial oxidation via lattice oxygen over $\mathrm{LaFeO}_{3}$ perovskite catalyst. J. Phys. Chem. B, 2006, 110(51): 25856.

[17] Keller G E, Bhasin M M. Synthesis of ethylene via oxidative coupling of methane I. Determination of active catalysts. $J$. Catal., 1982, 73(1): 9.

[18] Contractor R M, Garnett D I, Horowitz H S, Bergna H E, Patience G S, Schwartz J T, Sisler G M. A new commercial scale process for n-Butane oxidation to Maleic Anhydride using a Circulating Fluidized Bed Reactor. Stud. Surf. Sci. Catal., 1994, 82: 233.

[19] Mars P, Van Krevelen D W. Oxidations carried out by means of vanadium oxide catalysts [J]. Chem. Eng. Sci. Suppl., 1954, 3: 41 .

[20] Bordes E, Contractor R M. Adaptation of the microscopic properties of redox catalysts to the type of gas-solid reactor. Top. Catal., 1996, 3(3-4): 365.

[21] Alifanti M, Kirchnerova J, Delmon B. Effect of substitution by cerium on the activity of $\mathrm{LaMnO}_{3}$ perovskite in methane combustion. Appl. Catal. A, 2003, 245(2): 231. 